Experiments on Electrolysis. - Part I. Change of Density of the Electrolyte at the Electrodes

This content has been downloaded from IOPscience. Please scroll down to see the full text. 1887 Proc. Phys. Soc. London 9157

(http://iopscience.iop.org/1478-7814/9/1/322)

View the table of contents for this issue, or go to the journal homepage for more

Download details:

IP Address: 131.215.225.9

This content was downloaded on 02/10/2015 at 20:38

Please note that terms and conditions apply. 
XXII. Experiments on Electrolysis.-Part I. Change of Density of the Electrolyte at the Electrodes. By W. W. HaLDANE GEe, B.Sc., Assistant Lecturer in Physics, and H. HoLden, B.Sc., Bishop Berkeley Fellow in Physics, of the Owens College, Manchester*.

WHILST studying some electrolytic polarization phenomena with palladium electrodes in dilute pure sulphuric acid, a liquid was seen, after a reversal of the current, to flow downwards in streaks from the anode. Not being able to find any reference to the formation of streaks, for whose appearance the reversal of the current was necessary, it was decided to investigate their character. Further, it was thought that the occluded hydrogen might, on reversal of the current, unite with the nascent ion liberated at the anode, and thus effect chemical changes of an interesting character.

Some little care in observation and adjustment of the light is necessary in order to see the streaks, which, like the surrounding electrolyte, are colourless, and are only visible on account of the difference between their index of refraction and that of the main bulk of the electrolyte. A ressel with parallel sides of good plate-glass was employed, and a mirror used to reflect light obliquely into the cell. The arrangement which has been found to be most convenient is shown in the figure, and consists of a cell made of two pieces of plate-glass about 15 centim. square. A piece of india-rubber, 25 centim. long and 3 centim. square section, is bent in a semicircular form and clamped between the two glass plates by means of four iron screw-clamps. In this way a water-tight cell, about $1 \cdot 5$ centim. broad, is obtained which may readily be taken to

* Read February 25, 1888.

This is the first of a series of papers on Electrolysis and Electrolytic Polarization, descriptive of experiments made, during last year, at the Owens College Physical Laboratory. An abstract of the experiments made, to the end of August 1837, was submited to the British Association Meeting at Manchester. We desire to acknowledge the assistance received up to that time from Mr. C. H. Lees, B.Sc., Derby Mathematical Scholar of the Owens College. His cooperation has since been discontimued, owing to absence at Strasburg. 
pieces for the purpose of cleaning. The electrodes have usually consisted of two pieces of palladium, about $\cdot 05$ centim.

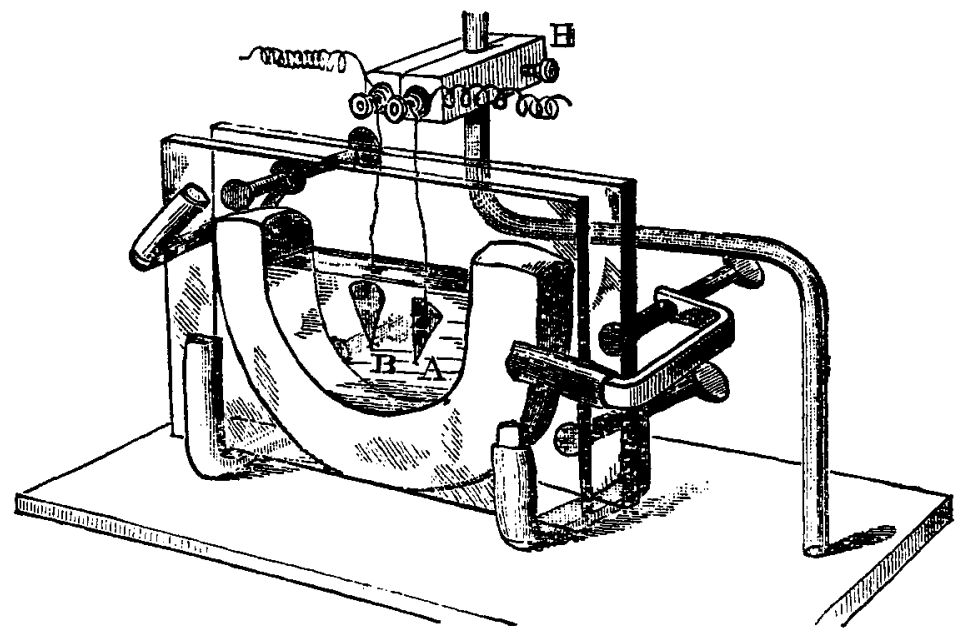

thick and with a surface of 5 square centim., fastened to phatinum wires and supported by means of a convenient cleretrode-holder.

Streaks olitained in dilnte pure Sulphuric Aicid.

The electrodes were first heated to redness in order to drive out any occluded gas, and then cleaned by meins of glasspaper. 'They were then pliced, by means of the electrodeholder $\mathrm{H}$, in the electrolytic coll containing dilute pure sulphuric acil. The current was sent from one electrode (A) to the other (B), which is thus the kathode, for a cortain time and then reversed. On reversal no gas appears at first from 13, which is now the anode, but strealss resembling a dense liquid are with careful observation seen flowing downwards from this electrode. After a time, depending on the size of the electrodes, the strength of the current, and its duration in the first direction, evolution of gas at B begins, and the strealss simultaneously cease to be visible. The streaks are to be seen streaming from one electrode only at a time, and always descend from that palladium electrode which first serves as larthode and then as anode.

When platiuun electrodes are substituted for the palladium ones, wo have not been successful in obtaining the streaks; it 
is, however, only necessary that one of the electrorles should bo palladium in order to obtain the streaks.

An experiment was made in orler to ascertain the part which the reversal of the current plays in the formation of the strealss. The current was sent in one direction thronuh the electrolyte, the palladium electrodes then taken ont, washed, and their surface cleaned with glass-paper. On now ruversing the current and replacing the electrodes, the stralis are quite as evident as if the electrodes had not been taken out. But if, on taking the electrodes out, they are heated to redness instead of merely having their surface cleaned, on replacing them and reversing the current the streaks are not seen, and giss appears immediately from the anode. TVe concluded from this experiment that the function of the current in the first direction was to fill with hydrogen that electrode at which the streaks appoar in the second direction of the current; and that the reason why, after a time, the stroaks ceascd to be visible, and simultaneously gas brgan to be evolved at the anode, was that by this time all the occluded hydrogen had been used up. It was therefore thought probalble that the streaks were formed by a combination of the occluted hydrogen with the ion (either $\mathrm{SO}_{4}$ or some of its components, such as oxyenen) which is liberated at the anodre in the second direction of the current. The theory that the streaks were composed of concentrited sulphuric acid sermest open to great objections; for we know that concentration takes place at the anode in dilute sulphuric acid without a rersal of the current, and also does not depend on the use of palladium olectrodes; but the streaks are, as is shown above, only to be obtained after a reversal of the current, and are not to be obtained with platinum electrodes. It was therefore decided to test, as far as practicalble, other possible comlinations, such as hydroxyl (tho streaks cannot le composed of water, for they are denser than the surrounding electrolyte), a salt of palladium, \&c.

\section{Testing for IIydroxyl.}

The palladium electrodos used were rectangular strips, about 2 centim. long and 3 centim. broad, placed vertically in 10 per-cent. sulphuric acid. For the purpose of collecting the 
streaks a capillary glass tube had one end blown out into the shape of a small funnel, and was bent so that it could be lowered into the electrolyte with the finger pressed on the upper end, which projected from the cell, until the funnel part was immediately below the electrode. After a reversal of the current the funnel part was placed in this way under the anode, from which the streaks were flowing. The finger was then removed from the top end of the tube, and the funnel acted as a reservoir for the denser liquid flowing from the anode. As soon as gas appeared at the anode the finger was replaced on the top end of the tube, the latter being then removed and its contents emptied into a test-tube. This proceeding was repeated many times (at least fifty), and the total liquid collected was tested for hydroxyl by the addition of a few drops of a solution of titanic acid in strong sulphuric acid. No trace of a coloration could be perceived, and thus the presence of hydroxyl was not proved *.

* The test, which is a delicate one, has been greatly employed by Richarz in lis experiments on the mode of appearance of hydroxyl at the anode in sulphuric acid (Wied. Ann. xxxi. p. 912, 1887). He concludes that the appearance of hydroxyl at the anode is caused by the purely chemical decomposition of the "Uebersch wefelsäure" (Berthelot's $\mathrm{S}_{2} \mathrm{O}_{\gamma}+$ $\mathrm{IH}_{2} \mathrm{O}$ ), which is first formed there. Traube, Berichte der deut. chem. Gesell. xviii. p. 3348 (1888) gives the equation for this decomposition as

$$
\mathrm{S}_{2} \mathrm{O}_{6}\left(\mathrm{O}_{2}\right) \mathrm{H}_{2}+2 \mathrm{H}_{2} \mathrm{O}=2 \mathrm{II}_{2} \mathrm{SO}_{4}+\mathrm{II}_{2}\left(\mathrm{O}_{2}\right) \text {. }
$$

Richarz confirms Berthelot's statement that no hydroxyl is formed at the platinum anode unless the strength of the acid is abore 60 per cent. As we obtained the strealss in 10-per-cent. acid, the abore fact lends additional strength to the view that the streaks are not hydroxyl. They might consist of $\mathrm{II}_{2} \mathrm{~S}_{2} \mathrm{O}_{3}$ (Ueberschwefelsäure), which Berthelot has shown to be a minor secondary product formed during the electrolysis of sulphuric acid, whether dilute or strong (see Ann. de Chim. et de 17yss. xiv. 1878, and $x x i .1880$ ). The quantity so formed at a platinum anodts is small, and would apparently be still smaller at a palladium nnode charged with hydrogen if the fullowing rensoning be accepted. Let us first consider the case of an anode unclarged with hydrogen. Assuming that the ion liberated at the anode is $\mathrm{SO}_{4}$, the simplest hypothesis to account for the secondary reactions is that part of the $\mathrm{SO}_{4}$ combines directly with the $\mathrm{II}_{2} \mathrm{SO}_{4}$ of the electrolyte to form $\mathrm{H}_{2} \mathrm{~S}_{2} \mathrm{O}_{8}$, whilst the remainder of the $\mathrm{SO}_{4}$ (probably by far the greater part) acts on the $\mathrm{Ir}_{2} \mathrm{O}$ of the electrolyte, forming $\mathrm{I}_{2} \mathrm{SO}_{4}$ and liberating $\mathrm{O}$. Should, however, the anode be charged with II, the SO, would have en additional tendency to combine directly witb the $\mathrm{II}$, forming $\mathrm{H}_{2} \mathrm{SO}_{4}$. This tendency would probibly greatly 


\section{Testing for Palladium Salts.}

A supply of the liquid having been obtained by a similar process to the above, a, solution of potassium iodide was added to it, but no evidence of the presence of palladium was obtained.

\section{Streaks oltained in Phosphoric Acid.}

Similar streals were obtained in solutions of pure orthophosphoric acid by adopting exactly the same procedure as with sulphuric acid.

\section{Streaks obtained in Caustic-Soda Solution.}

In this case also streals were obtained descending from one of the electrodes, but the conditions necessary for their appearance are very different to those in the ease of sulphuric and phosphoric acids. No previous reversal of the current is necessar'y, and the streaks descend from the kathode immediately the current is passed. The gas (hydrogen) formed at the kathode is at first alsorbed, and the streaks are seen to descend as long as the alssorption takes place; but, when gas begins to be evolved briskly, the streaks disappear. By very careful observation it is seen that the liquid of which the streaks are composed is still formed, but is carried up in the current of gas to the surface of the electrolyte, from which it rebounds, giving the electrolyte round the kathode the peculiar wavy appearance which accompanies the incomplete mixing of two liquids of different densities, such as two strengths of the same solution.

\section{Explanation of the Caustic-Soda' Streaks.}

This experiment led us to infer that the streaks in the caustic-soda solution are composed of concentrated alkali, which is known to be formed at the kathode, and that the

exceed the other two, so that if sufficient occluded II be present, it would be expected that neither $O$ would be liberated, nor II.SS $\mathrm{S}_{2} \mathrm{O}_{\mathrm{H}}$ formed. It is known that there is no evolution of $O$ under these conditions; and it would be interesting to estimate the relative amounts of $1 \mathrm{I}_{2} \mathrm{~F}_{2} \mathrm{O}_{\mathrm{N}}$ produced at a palladium anodo when charged and when uncharged with II. The I I. $\mathrm{S}_{2}\left(\mathrm{O}_{8}\right.$ could be quantitative]y determined by the method used by Richarz (loc. cit. p. 017). 
alsence of evolution of gas from that electrole is a necessary condition for their appearance and stealy downward flow. The part played by the palladium in the formation of the streaks is, according to this theory, that of absorbing the hydrogen, which otherwise, in escaping from the electrode, would carry the concentrated solution along with it to the surface and thus prevent the formation of the streaks.

\section{Explanation of Streaks in general.}

Since in acids concentration occurs at the anode, the descending streaks, if seen at all, should be seen at that electrode. But taking sulphuric acid as an instance, oxygen is given off at the anode, and the palladium cannot retain it sufficiently to stop its evolution, and thus the concentrated acid will be carried up by the current of oxygen and escape observation. But if the electrode has been filled with hydrogen by previously serving as kathode, the evolution of oxygen on reversal of the current is prevented either by its direct union with the occluded hydrogen, or by the union of the ion $\mathrm{SO}_{4}$ with the hy. drogen. No gas being evolved, the concentrated acid is able to flow downwards in streals. This explanation is borne out by the experiments with sulphuric acid detailed above, in which it was seen that, on placing freshly-heated palladium electrodes in sulphuric acid, gas is immediately evolved at the anode; but if that electrode has been previously filled with hylrogen, the oxygen, on reversal of the current, does not appear for some time at the anode, and the streaks are visible during this period.

Concentration of the solution at one electrode is accompanied by a weakening of the solution at the other electrode. 'I'herefore, as in acids the weakening takes place at the kathode (at which the gas is absorbec.), we should expect to see streaks ascending from that electrode without a previous reversal of the current. On trying the experiment with palladium electrodes placed horizontally in dilute sulphuric acid, this supposition is found to be warranted. The reason why the streaks ascending from the kathode were not seen in our earlier experiments is, that the electrodes had been placed vertically with their top edges a little below the surface of the electrolyte, and so the weakened solution in 
ascending had naturally clung to the surface of the electrode and thus escaped detection.

The late Professor Christiani (in a work* to which we shall refer more fully in a subsequent papor) gives three instances in which he observes streaks from the electrodes, but does not offer any explanation of their mode of formation. He cites the cases of zinc electrodes in concentrated zinc sulphate and copper electrodes in concentrated copper sulphate $\dagger$. In these cases, without a previous reversal, he observed streaks descending from the anode and ascending from the kathode at the same time. These results are evidently in accordance with the theory proposed above: no gras is given off at either electrode, and so the concentrated solution is allowed to descend in streaks from the anode and ascend in streaks from the (horizontal) kathode.

Another confirmation is given by the behaviour of potassium sulphato during electrolysis. After a curre:t has been passed in the same direction through potassium sulphate, it is found, on testing with litmus paper or by cautiously adding litmus solution, that the bottom strata of liquid have become alkaline and the top strata acid, the solution being originally neutral. It follows from this that the alkaline sor $11, \mathrm{nn}$ produced at the kathode is denser than the electrolyte, which itself is denser than the acid solution produced at the anode. Therefore, according to theory, the streaks, if seen at all, should descend from the kathode and ascend from the anode. This is fully borne out by experiment. Starting with freshly-heated palladium electrodes, on putting on the current we immediately see the streaks descending from the kathode; and after a reversal of the current other strealss may simultaneously be detected rising from the anode.

The best conditions for secing the streaks seem to be:-

(1) a horizontal electrode of small surface $f$,

* "Ueber irreciproke Leitung electrischer Strüne," 1876, R. Friedänder; Wied. Elect. ii. p. 727.

$\dagger$ Chri tiani, loc. cit. p. 100.

$\ddagger$ A vertical electrode may be used with alvantage if it is well below the surface of the electrolyte and if it is sumpended by a horizontal wire, so that the view of the electrolyte above and below it is not interrupted. An angular electrode is very convenient, as the lichuid fluws most realily from points. 
(2) a strong current,

(3) no evolution of gas.

The conditions (2) and (3) are incompatible with the use of platinum electrodes in dilute sulphuric acid: it is quite possiblo, however, that even in this case matters might be so arljusted that some trace of the formation of the streaks could be detected. In the case of platinum electrodes in solutions of sulphates of metals which do not act readily on water, such as zinc, copper, iron, \&c., the metal will bo deposited and no gas evolved at the kathode, and thus streaks of the weakened solution can be seen at that electrode*.

A direct proof that the streaks were formed of concentrated acid might be thought possible, in the case of sulphuric acid, on consideration of the following circumstances:-

(1) When strong sulphuric acid is dropped into dilute sulphuric acid, the strong acid sinks to the bottom of the containing vessel and remains undiffused for a considerable period.

(2) If collecting-vessels are placed under the electrodes and an arrangement fitted up by which the current may be periodically reversed, say overy minute, tho strealss will be formed at the electrodes and will stream into the collecting-vessels.

(3) If we now titrate with standard caustic-soda solution equal volumes of the liquid in the collecting-vessels and of the main bulk of the electrolyte, we ought to find that the formor is the more acid.

It may, howover, bo noticel that, assuming the streaks woro not concentrated acid, we should collect by this arrangement, not only the streaks, but also some of the concentrated acid which is formed at the anode. Thus, eren if the acid in the collecting-vessels did become stronger, it would scarcely prove that the streaks were the cause of thist.

From the experiments detailed above, thongh direct proofs are apparently not available, we may draw the following general

* Christiani noted the streaks with platinum electrodes in ferrous sulphate.

$\dagger$ Some observations have been made by this method, but the results Lave not been very definite. We lave designed an automatic cummu. tator which will reverse the current at intervals of 15,80 , or 60 seconds. This arrangement will enable us to collect more ensily the substance forming the straks. 
conclusions:-That when gas is not evolved at an el yotrode, streaks are formed there. These are due either to a concentration or weakening of the electrolyte, as in the case of solutions of acids and allialies and come salts (such as zinc sulphate); or, in the case of other salts (such as potassium sulphate), to a chemical change in the electrolyte, yielding at one pole allsili and at the other pole acid, producing solutions of different den-ity to the electrolyte. When gas is not evolved at an electrode these changes are still produced, but their effect in producing streaks is destroyed by the evolution of the gas.

In our next paper we hope to describe some experiments in which these effects become of great importance in changing the resistance of the electrolyte.

XXIII. On a Method of Deter'mining the Difference between the phase of two Harmonic Currents of Electricity having the same Period. By Thomas H. Blakesley, M.A.*

Ir has been brought to my notice by both English and Foreign journals connected with science that a method of de termining the difference in phase of two Harmonic Currents of Electricity having the same period, which I invented and published some years ago, forms an important part of the subject matter of a paper communicated to the Royal Academy of Sciences of Turin, second series, vol. sxxviii, by Signor Galileo Ferraris, in which that philosopher lays claim to the invention above mentioned, producing it as original, with no sign of acknowledgment that the method has before been made public.

The method consists in employing the two coils of an electric dynamometer in a peculiar way. When an harmonic current is sent through the coils of such a dynamometer in series, its reading will measure the quantity $\frac{I^{2}}{2}$, where $I$ is the maximum value of such a current. In this way we may 